\title{
Military medicine
}

\author{
Michael J World
}

\section{Michael J World \\ MD FRCP L/RAMC, \\ Defence Medical \\ Services' Professor \\ of Military \\ Medicine, Royal \\ Centre for Defence \\ Medicine, \\ Birmingham; \\ Advisor in Military \\ Medicine, Royal \\ College of \\ Physicians; \\ Honorary \\ Consultant \\ Physician and \\ Nephrologist, \\ Queen Elizabeth \\ and City Hospitals, \\ Birmingham \\ Clin Med \\ 2007:7:218-23}

\section{The potential benefits of military intervention}

Most people might doubt that a military doctor could influence developments in medicine for the better. After all, the military are often perceived to be all about death and destruction. This article attempts to rectify this misconception. It needs to be remembered from the outset that armies are maintained by democratic as well as other forms of government. In the case of democracies, the armies are the agents of the electors of such governments. There may be occasions where the timely use of military power can minimise death and destruction when compared with other forms of intervention such as economic sanctions. However more acceptable the latter may appear, sanctions may not bring horrific situations where loss of life is prevalent to a swift end but may actually result in little or no limitation on the homicidal activities of odious regimes. Providing and improving medical support to the army so that it is fit to do its job when it is wisely deployed therefore confers a potential benefit. In addition, military medical observations and developments can also be beneficial to civilian populations. In the paragraphs that follow selected evidence to support these statements will be examined.

\section{Professor of Military Medicine}

The influence of the Defence Medical Services' Professor of Military Medicine extends through four specific roles: clinical practice, operational duties, research and teaching. All are interlinked. Clinical practice maintains personal medical skills. In contrast, operational duties concentrate the mind on the problems of the operational environment both in terms of the logistical limitations on practice and the specific medical problems encountered. Research provides the answers to problems perceived and informs doctrine taught to medical officers, both naive and experienced, departing for operational duties.

\section{Securing social stability}

The practice of medicine is continually changing as a consequence of the varying challenges which have the potential to terminate lives prematurely.
Liberating humanity from this fear enhances the confidence that individual objectives will be achieved, benefiting society as a whole. Medicine is just one of the factors which support the evolution of society. Stable democracy encouraging investment promotes development of an infrastructure designed to nurture a safe environment where clean drinking water, safe sewage disposal and reliable food supplies are virtually guaranteed. Working as a military physician, one has plenty of opportunity to see the perpetual struggle in developing countries where continual war and premature death halt any significant development and condemn the population to subsistence. Equally, the military physician experiences the ultimate physical challenge to continued existence that warfare brings. It is these experiences that might be shared with civilian colleagues for the benefit of the whole population.

Prejudice may have prevented objective assessment of military medical practice. For example, it remains a common belief that British military medical practitioners treat their own combatants first: this is not true. All military casualties are treated on the basis of medical priority irrespective of the type of uniform worn. There is an international forum (International Congress of Military Medicine) for military doctors to meet on a regular basis and pool their experiences for the benefit of all. Every aspect of military medicine is significant for civilian practice and, consequently, military medicine beneficially influences each area.

\section{A new opportunity}

The last UK military hospital closed in 2001 (Fig 1). The military clinical staff had been migrating to new Ministry of Defence hospital units (MDHUs) based at host NHS hospitals since 1996. Apart from an administrative centre, the MDHUs were not separated physically as military wings: the military clinical staff and military patients were integrated into the civilian hospital. One benefit was that, when called for deployment, the absence of military personnel was more easily compensated by their more numerous civilian colleagues. A new opportunity has arisen for the previously cloistered military staff to influence general medical philosophy. 


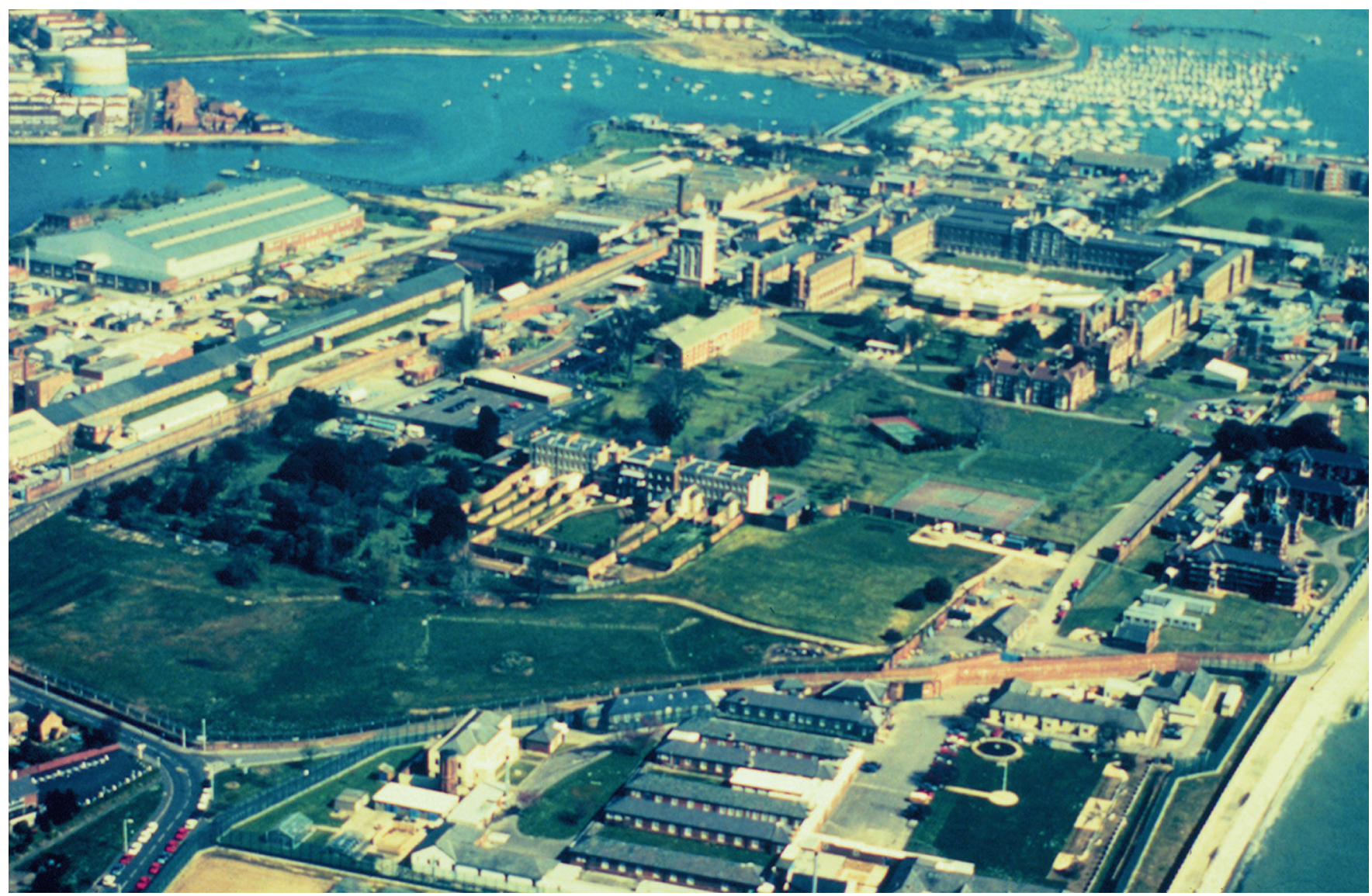

Fig 1. The last military hospital in the UK, Royal Hospital Haslar (formerly the Royal Naval Hospital, Haslar), closed in 2001.

\section{The challenge to military personnel}

Contrary to popular belief, the majority of casualties on operations arise from medical rather than surgical conditions. The distribution of admissions to a military field hospital in April 2003 was $71 \%$ medical and $29 \%$ surgical. In every conflict, disease and non-battle injury have been far more likely to prevent the successful completion of a military mission. Even in conflicts such as the First World War, where the carnage of the battlefield is more easily remembered, the medical data reveal that disease contributed by far the greater proportion of morbidity and mortality. Much of this arises from extreme environmental conditions that reduce the threshold for other diseases. Raising the morbidity threshold improves military effectiveness.

\section{The military medical strategy}

Ensuring that military personnel are equal to the task starts at the most basic level of careful selection for physical fitness (Fig 2). This is then promoted to a higher level during military training where cardiopulmonary reserve is developed and later maintained during service by six-monthly tests. Substandard performance is followed by a further attempt after one week and, in the absence of improvement, referral to a military medical officer. In this way the threshold for detection of disease is lowered permitting earlier intervention with a greater likelihood of effective remedial action. Similarly, dependence on expensive sophisticated investigational facilities, with possible limited availability, as the sole means of improving early diagnosis is somewhat reduced. Studies of military recruits subjected to uniform environmental stimuli have enabled correlations to be made between genotype and the magnitude of improvements in physical performance during basic military training. ${ }^{1-5}$

\section{Civilian comparison}

Most human organ systems have a remarkable reserve capacity. It is only when this capacity is severely reduced that symptoms will arise in patients who make few physical demands on their bodies. By contrast, the military population is pushed to the limits of human physiology and, occasionally, exceeds even its enhanced capability with potentially serious medical consequences. In military personnel, symptoms, albeit less specific ones (eg reduced exercise tolerance), generally arise much sooner in any disease process. Cigarette smoking has a pernicious effect on human physiology but it will degrade cardiorespiratory performance causing symptoms at an early stage but only if exertion is attempted. Similarly, increasing obesity will only compromise physical performance at an early and more easily remediable stage if there is a frequent physical challenge. 
Fig 2. Selection testing for the Parachute Regiment.

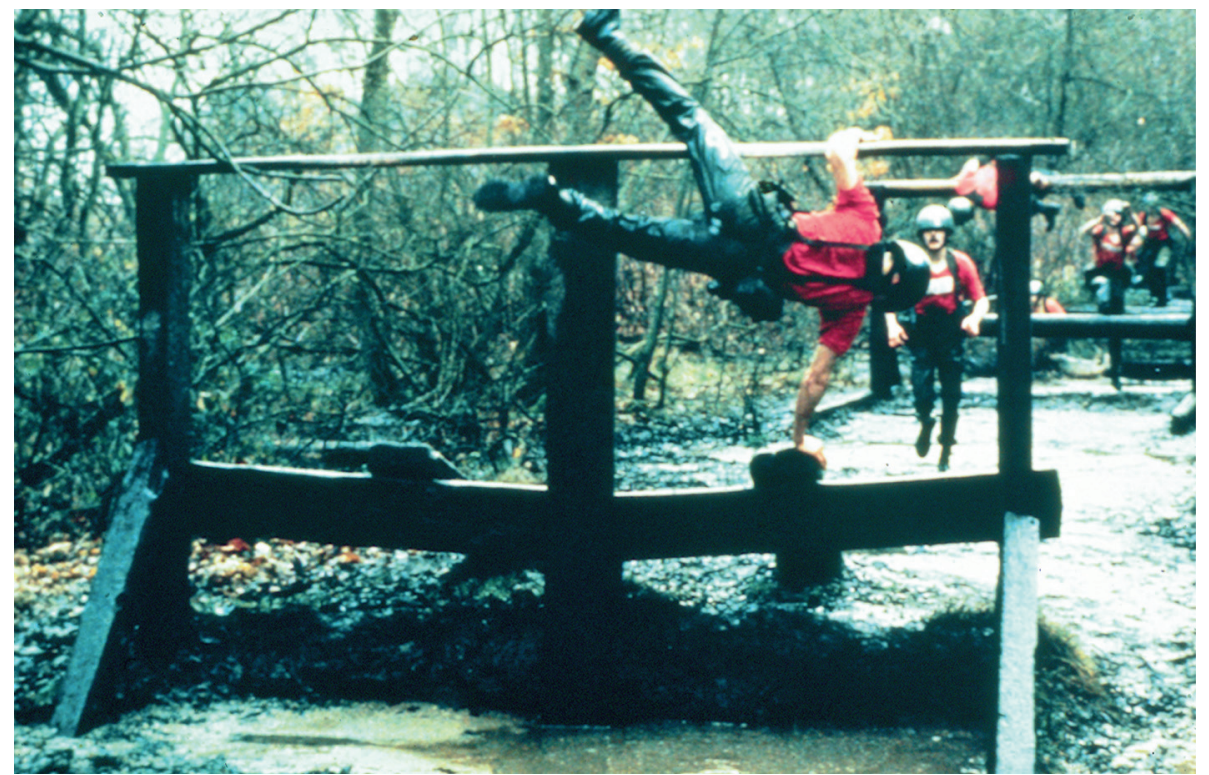

Continued employment and promotion (with increased pay) for military personnel is largely dependent on satisfactory performance that is not compromised by a lack of physical fitness. Regular medical examination complements this personal motivation and, as far as possible, military capability is not compromised by inferior physical performance. Staffing military posts from an ageing population is difficult: every trained soldier is essential and replacement may be impossible. It is evident that standards have to be high if military effectiveness is not to be compromised.

\section{Preventive medicine}

It will be apparent that preventive medicine is the cornerstone of military medical practice. Enhanced fitness, medical surveillance, prophylactic interventions (physical, immunological and pharmacological) appropriate to the theatre of operations and snap inspections for the use of illegal drugs all play their part. Civilian colleagues may question the need for all this when effective stand-off weaponry (stealth bombers delivering laserguided munitions, cruise missiles, multiple rocket launcher systems, helicopter-borne artillery) which can effectively neutralise opposing forces limits the need for close quarter physical engagement. However, military operations often entail extreme environmental challenges (Figs 3 and 4) which include temperature, humidity and altitude. Only those forces capable of operating effectively in such hostile environments will be successful militarily. The relevance to civilians may be increasing. Global warming may radically change the environment in currently temperate locations with an adverse effect on indigenous civilian populations.

\section{Influencing the civilian population}

The military experience suggests that if it were possible to increase the expectation of physical capability in the civilian population, personal motivation might reduce the prevalence of obesity and exposure to toxic substances such as drugs, tobacco and alcohol. This would benefit society at large, improving life expectancy and reducing morbidity with attendant reductions in the financial cost of absence from work, training new personnel and providing for dependent surviving relatives. Such expectation has to be started at an early age. As much emphasis should be placed on physical as well as mental prowess in schoolchildren. It is the physical capability that has been relatively ignored in recent decades and a return to competitive sport would yield many dividends provided it fosters greater physical activity in adult life.

\section{Changing diagnostic evaluation}

Assessing physical capability in civilian patients as a means of assessing physical reserve needs to be given higher priority to facilitate early diagnosis. While assessment of the indexed maximum oxygen consumption rate $\left(\mathrm{VO}_{2} \mathrm{I}_{\max }\right)$ and its relation to predetermined age-related $95 \%$ confidence limits would be a counsel of perfection, there is a need for simple tables of expectation. The military sets age-related standards for a 1.5 mile running time and the numbers of push-ups and sit-ups executed in two minutes. Similar standards should be promoted for the general population. Providing electric buggies should be considered an intervention of last resort to preserve independence rather than an early means to continue an unhealthy lifestyle.

\section{Assessing system-specific reserve}

In nephrology, the recent introduction of routine reporting of estimated glomerular filtration rate (eGFR) will enhance early detection of sequential diminution of renal reserve. A normal eGFR, however, may lull primary care doctors into a sense of false security unless similar emphasis is placed upon urine testing. Civilian attitudes in relation to this important test need 
Fig 3. The challenging environmental profile throughout the year in Basra, Iraq.

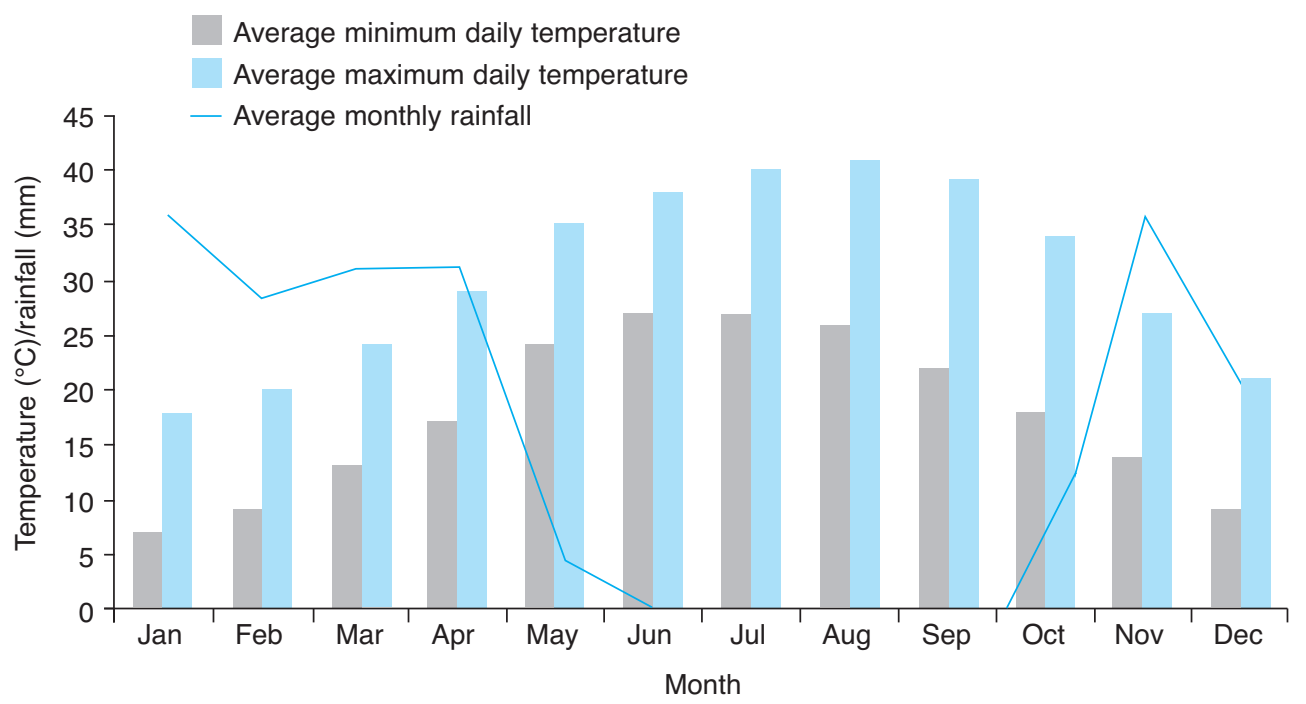

to be diverted from the music hall joke perception held by so many. There is no question that even in a fit military population referral of patients with persistent urinary abnormalities (present on three occasions at one week intervals) has paid dividends. Provided physical exertion in the previous 24 hours in all military personnel, menstruation in females and recent sexual activity in males are excluded as a cause of this, early nephrological assessment will discover glomerulonephritis and its cause at an early stage so that exposure to adverse environmental conditions is avoided and early use of appropriate measures (eg blood pressure control with ACE inhibitors) will improve renal longevity. The environmental protection is not limited to physical challenges (heat and dehydration), important as this is, but includes protection from exposure to novel antigens that may precipitate exacerbation or relapse. It should be remembered that in the young military population, immunoglobulin $\mathrm{A}$ (IgA) nephropathy is the most prevalent cause of renal morbidity and that respiratory and gastroenterological viral infections, so common on operations, are frequent precipitants of

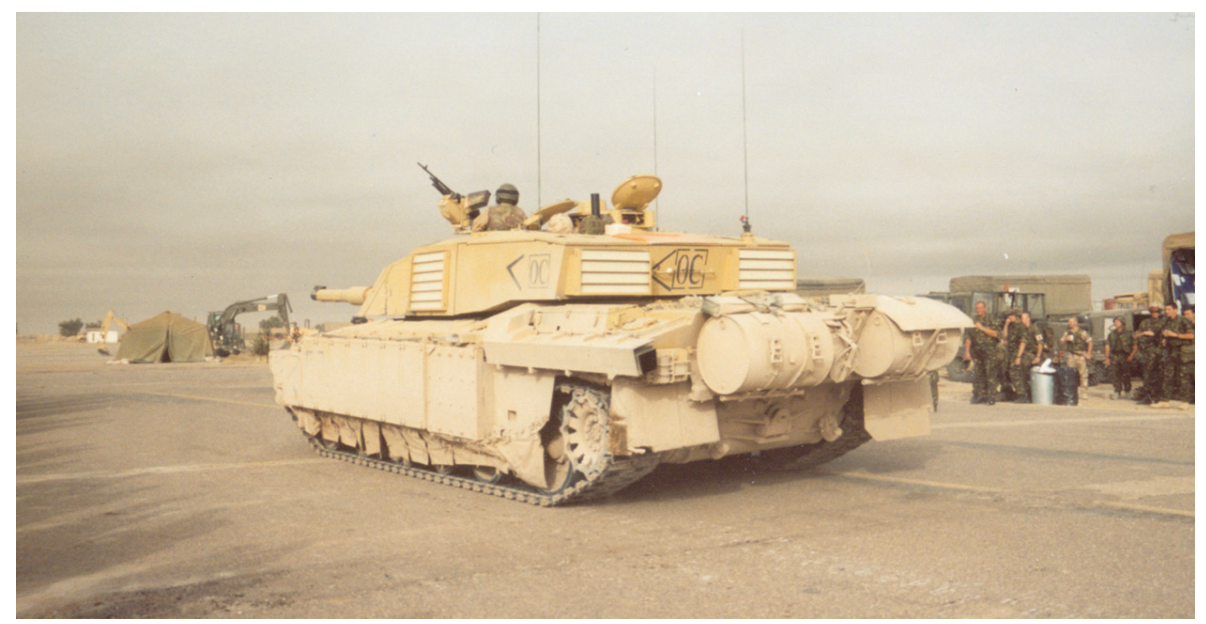

Fig 4. A Challenger 2 main battle tank outside Basra in 2003. Confinement within military vehicles compounds the environmental challenge. renal inflammation where a prior propensity exists. The early detection of glucosuria, excess nitrite, leukocyturia, bilirubinuria and hyperurobilinogenuria will be an additional bonus.

It is surprising how often individuals with single kidneys present themselves for medical assessment before enlistment or commissioning. Those with congenital unilateral renal agenesis or nephrectomy in infancy have compensatory hypertrophy of their sole kidney such that GFR is usually undiminished. Hitherto, patients with single kidneys with no evidence of renal disease and a GFR of at least $60 \mathrm{ml} / \mathrm{min}$ have been accepted for service but recent operational data has challenged the wisdom of this and a more circumspect attitude may have to be adopted (Fig 5).

\section{Making one's presence felt}

Within the new civilian hospital milieu, there is a great opportunity for military staff to influence their civilian colleagues. Distinctive military uniforms aid identification both within the military and civilian working community. Civilian clinical students will be more likely to enquire about the nature of military clinical life on operational duties. This extends from the bedside to the lunch queue. Although most personal professional telephone calls may be from Birmingham, calls will occasionally be from the Balkans, Basra, Belize, Brunei or Camp Bastion where a military clinical situation demands a military medical perspective. This will encompass conditions less likely to be encountered in the UK such as hantavirus infection, viral haemorrhagic fever, leptospirosis, malaria, leishmaniasis or military toxicological 


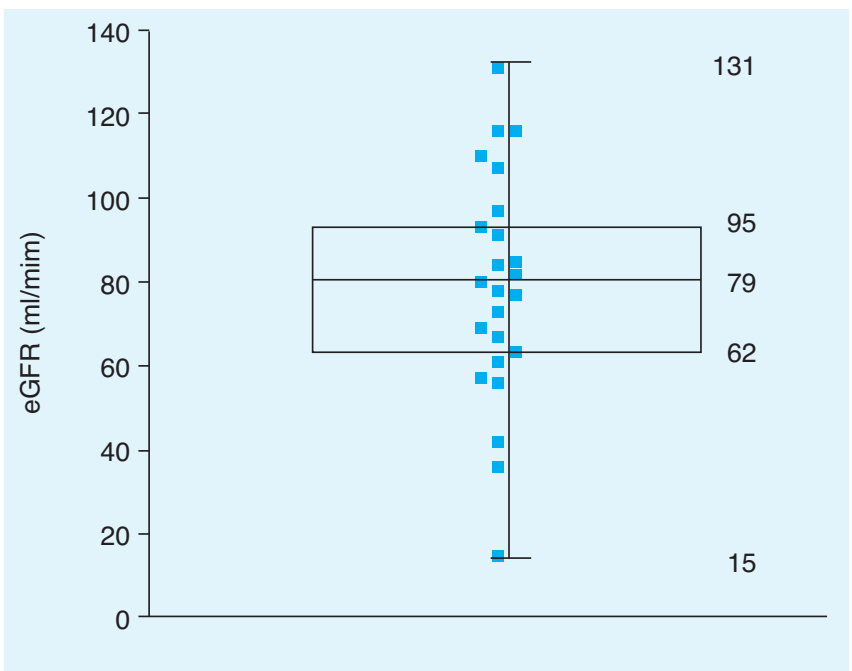

Fig 5. Distribution of estimated glomerular filtration rate (eGFR) (Cockcroft-Gault, $\mathrm{ml} / \mathrm{min}$ ) displayed as a 'box and whiskers' plot showing median, interquartile range and range of data in $\mathbf{2 5}$ cases of heat illness admitted to a military field hospital during the summer of 2005 in Basra, Iraq. Numbers to the right show the values of upper limit of range, upper quartile, median, lower quartile and lower limit of range respectively.

challenges. The mere incorporation of such discussions in audible telephone conversation enhances differential diagnostic consideration by civilian colleagues.

Military patients in civilian hospitals give incentive for civilian colleagues to acquire military medical information. Presentations by military clinical staff at grand rounds and seminars can illuminate the environmental, tropical and toxicological aspects that may complicate a standard insult. Survival from trauma, burns and infection will always be enhanced by superior physical fitness but compromised by additional insults such as exposure to nitrogen mustard and irradiation that reduce bone marrow responsiveness, enteric mucosal integrity with the potential for spontaneous Gram-negative infection and tissue regeneration.

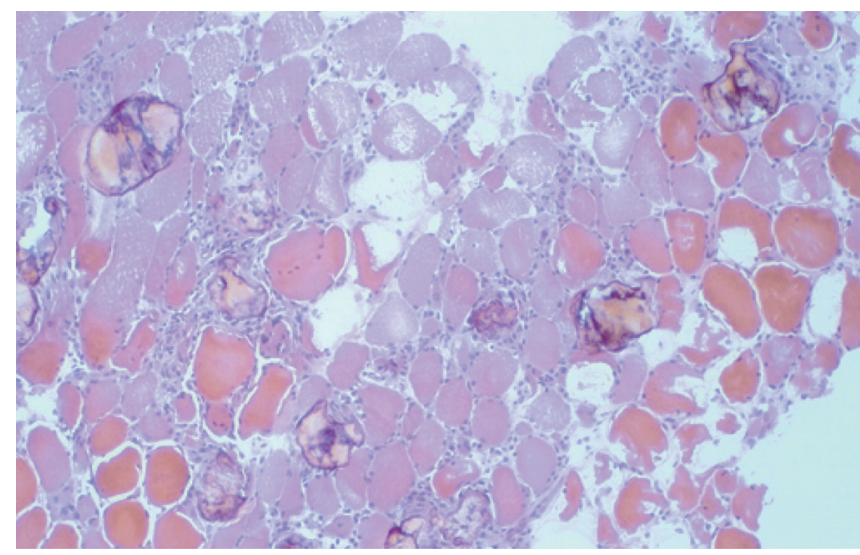

Fig 6. Severe rhabdomyolysis in a quadriceps muscle biopsy (stained with haematoxylin and eosin) of a case of heat injury that necessitated intensive care admission and haemodialysis. A full and complete recovery ensued eventually.
In an era of terrorist attack on civilian populations, acquisition of such information is not a waste of time. ${ }^{6}$

\section{The clinical pathology of heat}

This is an important military topic. It encompasses tissue damage (that ranges from mild rhabdomyolysis (Fig 6) to multiple organ failure with disseminated intravascular coagulation) at one end of the spectrum to hyponatraemia with compensatory electrolyte changes compatible with secondary hyperaldosteronism at the other. In the latter case, the attendant risk of iatrogenic precipitation of central pontine myelinolysis due to overenthusiastic medical correction is not a small-print problem. All of these conditions can arise in otherwise fit military personnel and could change the clinical course of another medical condition necessitating awareness by civilian clinical staff.

\section{Assistance to host nations}

While non-governmental relief agencies provide the major assistance to civilians in war zones, there is a most satisfying opportunity to interact with professional military and civilian colleagues in foreign countries. While the priority is attention to military medical problems, the morbidity in the civilian indigenous population is important. Awareness of high carriage rates of HIV, prevalence of tuberculosis or zoonoses, such as rabies, cannot be ignored if the military population is to be protected. Isolation from the host community may not be completely possible, especially when peacekeeping patrols are an essential element of military activity, and is highlighted to new entry medical officers.

\section{Advising military commanders}

Medical officers are always advisory to commanders who have the unenviable task of deciding the importance of a military mission in relation to the casualties that can be sustained by a single operation. Provision of real-time casualty rates can influence the continuation of a given action in relation to a number of operational objectives whose successful execution is considered important for the whole military mission (Fig 7). ${ }^{7}$

\section{Civilian sports activities}

In an age where relatively unfit members of the civilian population are becoming more likely to undertake long distance running with a risk of lethal outcome (eg the Great North Run, 2005), knowledge of heat illness and its pathology is increasingly being requested. Military doctors receive special training on this: their civilian colleagues may benefit from similar education.

\section{Influencing medical concepts and research}

The major insults mentioned previously which threaten the lives of military patients are trauma, burns and infection. The 


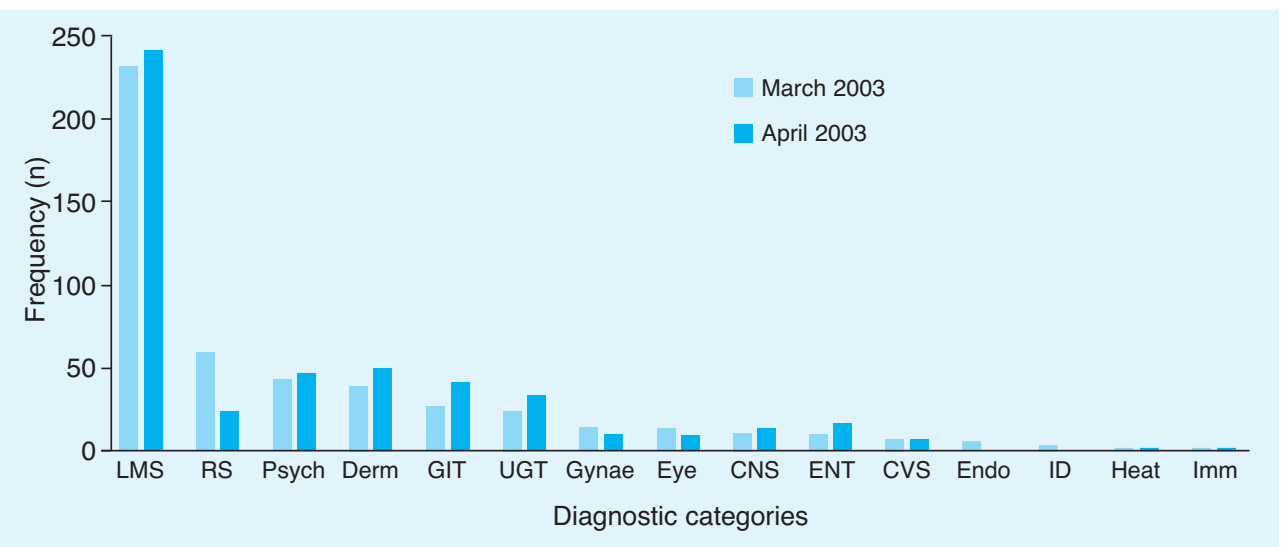

Fig 7. A comparison of the frequency distribution of military casualties requiring repatriation by air between diagnostic categories in March 2003 and April 2003. The invasion of Basra took place on 6 April 2003. There was a statistically significant difference $\left(\chi^{2}=32.5, v=14, p<0.003\right)$ but clinically it is evident that the invasion did not result in a great increase in casualties. The military objective was achieved with little cost in terms of casualties and could be considered very successful. The casualty rates in March reflect the dangers related to military deployments that are unrelated to large scale combat operations. ${ }^{7}$ CNS = central nervous system; CVS = cardiovascular system Derm = dermatology; Endo = endocrinology; ENT = ear, nose and throat; Eye = ophthalmology; $\mathrm{Gl}$ = gastrointestinal system; Gynae = gynaecology; Heat = heat illness; Imm = immunology; ID = infectious disease; LMS = locomotor system; Psych = psychiatry; RS = respiratory medicine; UGT = urogenital.

orthodox research approach is to devise new methods of treatment whose timely use will mitigate the effects of a specific insult. A novel approach is to consider that there may be a final common pathway in cellular loss. If such a hypothesis can be supported experimentally, understanding its nature may permit a prophylactic intervention which raises the threshold for tissue damage and conserves tissue viability under adverse circumstances. The confidence boost which combatants would gain from this would encourage the taking of greater risks to achieve previously untenable military goals. Quite simply, who dares more wins more. The potential benefits of this approach to civilian patients with severe physiological compromise undergoing major surgical interventions would be considerable.

\section{Summary and conclusion}

This article indicates the wide spectrum of influence, both current and potential, of military medicine. It impinges both directly and indirectly on the preservation of life by maintaining the capability of security forces through a number of mechanisms. These include selection, training and medical practice that encompass environmental, sports, tropical and toxicological medicine. It informs the combatant community of the consequence of its activities so that objective assessment of the human cost of continued military intervention can be considered. Now that military clinical staff practise in the civilian environment when not deployed, their opinion in specific clinical conditions could be beneficial when treating civilian as well as military casualties. Where terrorists threaten civilian populations, their expertise could be invaluable.

\section{Disclaimer}

The views expressed in this article are those of its author and do not purport to be those of Her Majesty's Government, the Ministry of Defence or its employees.

\section{References}

1 Montgomery HE, Clarkson P, Dollery CM et al. Association of angiotensin-converting enzyme gene I/D polymorphism with change in left ventricular mass in response to physical training. Circulation 1997;96:741-7.

2 Myerson SG, Montgomery HE, Whittingham M et al. Left ventricular hypertrophy with exercise and ACE gene insertion/deletion polymorphism. Circulation 2001;103:226-30.

3 Montgomery HE, Marshall R, Hemingway $\mathrm{H}$ et al. Human gene for physical performance. Nature 1998;393:221.

4 Brull D, Dhamrait S, Myerson S et al. Bradykinin BK2BR receptor polymorphism and the human left ventricular growth response. Lancet 2001;358:1155-6.

5 Brull DJ, Dhamrait S, Moulding R et al. The effect of fibrinogen genotype on fibrinogen levels after strenuous physical exercise. Thromb Haemost 2002;87:37-41.

6 World MJ. Bioterrorism. Clin Med 2004;4:161-4.

7 Gibbs H, World MJ. Did the invasion of Basra affect the UK casualty evacuation profile? 35th International Congress of Military Medicine. Washington DC, 2004. 